\title{
BIODEGRADAÇÃO DE ALCOÓIS, FTALATOS E ADIPATOS EM UM SOLO TROPICAL CONTAMINADO
}

\author{
Ieda Domingues Ferreira* e Dione Mari Morita \\ Departamento de Engenharia Hidráulica e Sanitária, Escola Politécnica, Universidade de São Paulo, Av. Prof. Almeida Prado,
} trav. 2, 83, 05508-900 São Paulo - SP, Brasil

Recebido em 23/11/09; aceito em 28/4/10; publicado na web em 17/9/10

\begin{abstract}
BIODEGRADATION OF ALCOHOL, PHTHALATES AND ADIPATES IN A TROPICAL SOIL. The adipic and phthalic acid esters are plasticizers, have low water solubility, high partition octanol/water coefficients (Kow) and accumulate in soil and sediments. These compounds are considered teratogenic, carcinogenic and endocrine disruptors chemicals. This study evaluated the bioremediation of tropical soil contaminated with plasticizers process wastes, in aerobic conditions, with and without introduction of acclimated bacteria. It was selected $200 \mathrm{~kg}$ of contaminated tropical soil for the biodegradation study. The plasticizers concentrations in soil ranged between $153 \mathrm{mgDOA} / \mathrm{kg}$ up to $15552 \mathrm{mgDIDP} / \mathrm{kg}$ and after 90 days of biodegradation, the lower removal efficiencies were $72 \%$ with a $1-2 \log$ simultaneous bacterial growth.
\end{abstract}

Keywords: bioremediation; phthalates; contaminated soil.

\section{INTRODUÇÃO}

Plastificantes podem ser definidos como aditivos de baixa volatilidade, utilizados para aumentar a processabilidade e a flexibilidade ou diminuir a dureza de materiais poliméricos. ${ }^{1}$ Os ésteres de ácidos ftálicos (ftalatos) e adípicos (adipatos) são plastificantes, caracterizados por sua baixa solubilidade em água, pelo alto coeficiente de partição octanol/água e pela tendência em se acumular nas partículas de solo e sedimento. São aditivos de resinas de cloreto de polivinila (PVC) e outras, como acetato de polivinila, poliuretano e resinas celulósicas. São também empregados na produção de repelentes de insetos, fibras sintéticas e cosméticos.

Os ftalatos de alta massa molecular são considerados teratogênicos e causam danos ao fígado, rins e órgãos reprodutivos, bem como disfunções endócrinas. ${ }^{2}$ A população em geral é exposta aos ftalatos através dos alimentos, água e ar, sendo as principais vias de contaminação a ingestão e a inalação. ${ }^{3,4}$

As perdas de ftalatos para o meio ambiente podem ocorrer durante a manufatura, distribuição, uso e disposição final dos plastificantes e de produtos plastificados. Devido à utilização global dos plásticos, os ftalatos têm sido detectados em diversos meios: ar, água e solo. ${ }^{5}$

Os processos de industrialização, que transformaram o mundo desde meados do século XVIII, e a exploração não sustentável dos recursos naturais dele decorrentes legaram à humanidade um conjunto de passivos ambientais, pelos quais ela sofre as consequências hoje e, se nada for feito, também sofrerão as gerações futuras. ${ }^{6} \mathrm{Um}$ destes passivos ambientais refere-se a solos e água subterrânea contaminados. Os diferentes países do mundo têm se esforçado na identificação de áreas contaminadas, na quantificação de seus impactos sobre a saúde e bem-estar público e na sua reabilitação. ${ }^{7-11}$

Um diagnóstico preliminar do Ministério da Saúde do Brasil, realizado entre 2001 e 2003, indicou a existência de 15.237 áreas potencialmente contaminadas no país; no entanto, um diagnóstico confirmatório, em 2004, identificou a existência de 689 áreas potenciais e efetivas com populações expostas ou sob risco de exposição a solos contaminados. No último inventário, realizado em 2007, este número foi de 700 áreas. $^{12}$

*e-mail: ieda.ferreira@poli.usp.br
No Estado de São Paulo, um panorama da situação foi apresentado em maio de 2002, quando a Companhia de Tecnologia de Saneamento Ambiental (CETESB) tornou pública a primeira relação de áreas contaminadas, na qual figuravam 255 sítios. A última atualização desta relação, divulgada em 2009, apontou a existência de 2514 áreas, das quais 17 continham ftalatos. ${ }^{13}$

A biorremediação tem sido usada para tratar solos contaminados com ftalatos. ${ }^{14,15}$ Para a aplicação desta técnica é necessário possuir dados de biodegradabilidade dos poluentes no solo. No entanto, segundo Semple et al., ${ }^{16}$ a biodisponibilidade de compostos orgânicos hidrofóbicos, como os ftalatos, é função do grau de adsorção dos mesmos aos minerais e à matéria orgânica do solo. Assim, a biodegradação destes compostos é diferente em solos tropicais e de regiões de climas temperados. Nas regiões tropicais úmidas, o intemperismo químico do solo é mais intenso, resultando em grande perda de bases e sílica e em acumulação relativa de óxidos de ferro e alumínio, processo denominado laterização. A intensidade de ação do intemperismo químico é diretamente proporcional ao aumento da temperatura. Quanto mais úmido e quente for o clima, maior é a profundidade do terreno submetido às alterações físicas e químicas, sendo estas últimas as mais intensas. ${ }^{17,18}$ Outra interferência da temperatura é em relação à quantidade de matéria orgânica no solo. Em condições de temperatura elevada e boa aeração, a mineralização da matéria orgânica ocorre rapidamente, liberando mais depressa os nutrientes para as plantas. Assim, em regiões de clima quente, as condições são favoráveis para o aumento da atividade microbiana, resultando, geralmente, em um solo pobre em matéria orgânica. ${ }^{18,19}$

Praticamente, não há dados sobre biodegradação de ftalatos em solos tropicais, o que motivou a realização da presente pesquisa.

\section{PARTE EXPERIMENTAL}

\section{Coleta de amostras do solo da área de plastificantes}

Foi retirada uma amostra de solo de $200 \mathrm{~kg}$, na profundidade de 1,0 $\mathrm{m}$ a partir do nível do piso industrial. Foi aberta uma cava nas dimensões 50 x 50x $100 \mathrm{~cm}$ (largura x comprimento x profundidade), sendo identificados água e óleo no local. 


\section{Caracterização do solo utilizado no ensaio de biodegradação}

Para a caracterização físico-química do solo contaminado, as amostras, após homogeneização, foram separadas em triplicata, na quantidade de $1 \mathrm{~kg}$ cada, sendo determinados o $\mathrm{pH}\left(\mathrm{H}_{2} \mathrm{O}\right)$; o pH $(\mathrm{KCl})$; a distribuição granulométrica; a densidade aparente; a umidade residual; a capacidade de campo e os teores de carbono orgânico, fósforo e nitrogênio totais; ferro; alcoóis e plastificantes.

Para a caracterização microbiológica, foi determinada a densidade de bactérias heterotróficas.

Aproximadamente $6 \mathrm{~kg}$ de solo homogeneizado foram distribuídos em duas bandejas de aço inox (AISI 304), isentas de contaminações, para secagem à temperatura ambiente, durante 4 dias. Tal procedimento foi efetuado em laboratório, na capela. Eventuais torrões, formados durante o período de secagem, foram desagregados. Posteriormente, o solo foi peneirado em malha com diâmetro de 2,0 $\mathrm{mm}$. Esta amostra foi denominada Branco 1 e o restante, Branco 2.

A caracterização geotécnica e mineralógica do solo contaminado foi efetuada na amostra Branco 1, sendo segregados $500 \mathrm{~g}$ para a determinação da composição mineralógica e 100 g, para a análise granulométrica. A composição mineralógica foi determinada através de difratometria e fluorescência de raios-X. O procedimento da difratometria de raios- $\mathrm{X}$, método do pó, consistiu no quarteamento da amostra de solo, obtendo-se uma porção de aproximadamente 20 g e posterior redução granulométrica, passando pela peneira mesh 200. A amostra resultante (alíquota de 1 a $3 \mathrm{~g}$ ) foi compactada sobre a cavidade de um suporte metálico ( $27 \mathrm{~mm}$ de diâmetro por $2,5 \mathrm{~mm}$ de profundidade) e introduzido no difratômetro de raios-x, marca PANanalytical, modelo Xpert PRO, com detector XCelerator. O procedimento da fluorescência de raios-X consistiu no quarteamento da amostra de solo, obtendo-se aproximadamente $50 \mathrm{~g}$ e posterior redução granulométrica, utilizando peneira mesh 400. A amostra resultante foi compactada em prensa de $20 \mathrm{t}$ e introduzida no equipamento de fluorescência de raios-x, marca PANanalytical, modelo AXIOS Advanced.

\section{Amostragem e caracterização do inóculo}

O inóculo utilizado para o teste de biodegradação dos poluentes do solo foi o lodo da estação de tratamento de águas residuárias da unidade industrial de plastificantes. As amostras de inóculo foram coletadas em recipientes de vidro (1 L) e posteriormente preservadas a temperatura de $4{ }^{\circ} \mathrm{C}$ até seu uso. Para caracterização do inóculo, foram determinados os seguintes parâmetros: $\mathrm{pH}$, temperatura, série de sólidos, nitrogênio Kjeldahl total, fósforo total, densidade de bactérias heterotróficas e concentrações de plastificantes e alcoóis.

\section{Ensaios de biodegradação}

Os ensaios de biodegradação dos poluentes do solo foram conduzidos em copos Griffin, durante 90 dias, em temperatura ambiente. Os frascos permaneceram fechados com papel alumínio e foram abertos uma vez por semana para homogeneização manual e coleta de amostras, durante todo o período de investigação experimental. Foram realizados ensaios utilizando amostras de solo Branco 1 (Ensaios I) e Branco 2 (Ensaios II), com micro-organismos indígenas e exógenos adaptados. Uma descrição dos mesmos é mostrada na Tabela 1.

\section{Monitoramento do processo de biodegradação}

Semanalmente, foram determinados a temperatura e o $\mathrm{pH}$ do solo. Após 30, 60 e 90 dias, foram retiradas amostras dos frascos para determinação dos teores de plastificantes e alcoóis.
Tabela 1. Descrição dos ensaios de biodegradação realizados com o solo contaminado

\begin{tabular}{|c|c|c|}
\hline \multicolumn{3}{|r|}{ Ensaios I - Solo Branco 1} \\
\hline Frasco & Variável & Descrição do ensaio \\
\hline Branco 1 & - & Controle \\
\hline 1 & Umidade & Umidade ajustada para $50 \%$ \\
\hline 2 & Nutrientes & $\begin{array}{l}\text { Umidade ajustada para 50\%, adição: } \\
\qquad 135 \mathrm{mg} \mathrm{N} / \mathrm{kg} \text { e } 30 \mathrm{mg} \mathrm{P} / \mathrm{kg}\end{array}$ \\
\hline 3 & Inóculo & $\begin{array}{c}\text { Umidade ajustada para 50\%, adição: } \\
9 \text { g SSV/kg (lodo) }\end{array}$ \\
\hline 4 & $\begin{array}{l}\text { Inóculo } \\
+ \text { nutrientes } \\
\end{array}$ & $\begin{array}{l}\text { Umidade ajustada para 50\%, adição: } \\
9 \mathrm{~g} \mathrm{SSV} / \mathrm{kg}, 135 \mathrm{mg} \mathrm{N} / \mathrm{kg} \text { e } 30 \mathrm{mg} \mathrm{P} / \mathrm{kg}\end{array}$ \\
\hline \multicolumn{3}{|r|}{ Ensaios II - Solo Branco 2} \\
\hline Frasco & Variável & Descrição do processo \\
\hline Branco 2 & - & Controle \\
\hline 5 & Inóculo & Umidade ajustada para 50\%,adição: $11 \mathrm{~g} \mathrm{SSV} / \mathrm{kg}$ \\
\hline 6 & $\begin{array}{l}\text { Inóculo } \\
+ \text { nutrientes }\end{array}$ & $\begin{array}{l}\text { Umidade ajustada para 50\%, adição: } 11 \mathrm{~g} \mathrm{SSV} / \mathrm{kg} \text {, } \\
\qquad 170 \mathrm{mg} \mathrm{N} / \mathrm{kg} \text { e } 37 \mathrm{mg} \mathrm{P} / \mathrm{kg}\end{array}$ \\
\hline 7 & Nutrientes & $\begin{array}{l}\text { Umidade ajustada para 50\%, adição: } \\
170 \mathrm{mg} \mathrm{N} / \mathrm{kg} \text { e } 37 \mathrm{mg} \mathrm{P} / \mathrm{kg}\end{array}$ \\
\hline 8 & Umidade & Umidade ajustada para 50\% \\
\hline
\end{tabular}

\section{Métodos analíticos empregados}

$\mathrm{O} \mathrm{pH}\left(\mathrm{H}_{2} \mathrm{O}\right)$, o $\mathrm{pH}(\mathrm{KCl})$ e os teores de COT, $\mathrm{P}$ total, $\mathrm{N}$ total, ferro e alumínio do solo foram determinados utilizando os métodos do Instituto Agronômico de Campinas ${ }^{20}$ e da Embrapa. ${ }^{21}$

A análise granulométrica foi efetuada pelo método da pipeta, em triplicatas, conforme o procedimento do manual de métodos de análises de solo. ${ }^{21}$

As determinações relativas à densidade aparente, umidade residual e capacidade de campo do solo foram realizadas de acordo com a Norma CETESB L6.350.22

A densidade de bactérias heterotróficas no solo foi determinada de acordo com a Norma CETESB L5.201, ${ }^{23}$ utilizando o meio R2A e a técnica pour-plate.

As determinações dos teores de alcoóis e plastificantes presentes nas amostras do solo e inóculo foram realizadas de acordo com os métodos 3540 e 8061A da United States Environmental Protection Agency - USEPA. ${ }^{24}$ Injetaram-se $2 \mu \mathrm{L}$ do extrato, obtido conforme método 3540, em um cromatógrafo gasoso CP-3380 da Varian, operando nas condições: injetor - modo splitless (sem divisão da amostra), temperatura no injetor $=280{ }^{\circ} \mathrm{C}$; gás de arraste - hélio, vazão $=48 \mathrm{~mL} / \mathrm{min}$; forno - temperatura inicial $=40^{\circ} \mathrm{C}$, durante 2 min, rampa de temperatura $=20^{\circ} \mathrm{C} / \mathrm{min}$, temperatura final $=280{ }^{\circ} \mathrm{C}$; coluna - RTX-35 Restec (cross-linked methylsilicone), com diâmetro interno de $0,53 \mathrm{~mm}$, comprimento de $30 \mathrm{~m}$ e espessura do filme de $1,5 \mu \mathrm{m}$. Gás de arraste: hélio, vazão $=7,0 \mathrm{~mL} / \mathrm{min}$, pressão $=30,30$ psi (constante), velocidade média $=86 \mathrm{~cm} / \mathrm{s}$; detector - detector de ionização de chama (FID), temperatura $=300{ }^{\circ} \mathrm{C}$, gases empregados (ar comprimido: $300 \mathrm{~mL} / \mathrm{min}$ e hidrogênio: $15 \mathrm{~mL} / \mathrm{min}$ ), gás make-up = nitrogênio: $30 \mathrm{~mL} / \mathrm{min}$.

$\mathrm{O}$ pH, a temperatura, a série de sólidos e as concentrações de nitrogênio Kjeldahl total e fósforo total no inóculo foram determinados conforme os procedimentos descritos no APHA, AWWA, WEF. ${ }^{25}$

\section{RESULTADOS E DISCUSSÃO}

\section{Caracterização do solo contaminado da área de plastificantes}

A área onde está localizada a indústria petroquímica é formada por rochas pré-cambrianas, constituídas de granitos e granodioritos, em parte gnaíssicos, micaxistos e meta-arenitos, bem como xistos 
miloníticos, encontrados em zona de movimentação tectônica. Abrange sedimentos geológicos terciários, constituídos por argilas, areias e cascalhos da Formação São Paulo e sedimentos aluvionares quaternários. Conforme o Mapa Pedológico do Estado de São Paulo, ${ }^{26}$ o solo da região é um Cambissolo Háplico.

A unidade industrial, de onde foram coletadas as amostras, está assentada sobre um aterro espesso, constituído de material retirado do entorno. A análise estratigráfica nos poços de monitoramento existentes detectou uma composição variada: camadas de material pedológico (cambissolos, organossolos, gleissolos) entremeadas com alteritas do pré-cambriano e areias do terciário e quaternário.

\section{Composição mineralógica do solo}

Os resultados da difratometria de raios $\mathrm{x}$ da amostra Branco 1 mostraram que o solo é constituído por caulinita $\left(\mathrm{Al}_{2} \mathrm{Si}_{2} \mathrm{O}_{5}\right)$, gibsita $\left(\mathrm{Al}(\mathrm{OH})_{3}\right)$, muscovita $\left(\mathrm{KAl}_{2}\left(\mathrm{Si}_{3} \mathrm{Al}\right) \mathrm{O}_{10}(\mathrm{OH}, \mathrm{F})_{2}\right)$ e quartzo $\left(\mathrm{SiO}_{2}\right)$. Os resultados das análises semiquantitativas de espectrometria por fluorescência de raios x, expressos em porcentual de óxidos, são mostrados na Tabela 2. Os maiores porcentuais de óxidos encontrados foram os de $\mathrm{SiO}_{2}(53,5 \%)$ e $\mathrm{Al}_{2} \mathrm{O}_{3}(31,9 \%)$, sendo os teores de ferro baixos $(2,24 \%)$.

Tabela 2. Resultados dos ensaios por fluorescência de raios X da amostra de solo Branco 1

\begin{tabular}{lccccc}
\hline Óxidos & $\%$ & Óxidos & $\%$ & Óxidos & $\%$ \\
\hline $\mathrm{Na}_{2} \mathrm{O}$ & 0,29 & $\mathrm{TiO}_{2}$ & 1,71 & $\mathrm{Rb}_{2} \mathrm{O}$ & 0,01 \\
$\mathrm{MgO}$ & 0,21 & $\mathrm{~V}_{2} \mathrm{O}_{5}$ & 0,02 & $\mathrm{SrO}$ & - \\
$\mathrm{Al}_{2} \mathrm{O}_{3}$ & 31,90 & $\mathrm{Cr}_{2} \mathrm{O}_{3}$ & - & $\mathrm{Y}_{2} \mathrm{O}_{3}$ & 0,01 \\
$\mathrm{SiO}_{2}$ & 53,50 & $\mathrm{MnO}^{2}$ & 0,02 & $\mathrm{ZrO}_{2}$ & 0,07 \\
$\mathrm{P}_{2} \mathrm{O}_{5}$ & 0,05 & $\mathrm{Fe}_{2} \mathrm{O}_{3}$ & 2,24 & $\mathrm{BaO}$ & 0,04 \\
$\mathrm{SO}_{3}$ & 0,09 & $\mathrm{ZnO}_{3}$ & - & $\mathrm{WO}_{3}$ & 0,03 \\
$\mathrm{~K}_{2} \mathrm{O}$ & 2,74 & $\mathrm{Ga}_{2} \mathrm{O}_{3}$ & - & $\mathrm{PbO}$ & 0,01 \\
$\mathrm{CaO}$ & 0,26 & - & & & \\
\hline
\end{tabular}

Os resultados das análises granulométricas da amostra de solo Branco 1, que continha 7,6\% de umidade, indicaram frações (médias de triplicata) correspondentes a 1,5 $\pm 0,4 \%$ de argila, $32 \pm 9 \%$ de silte e $67 \pm 8 \%$ de areia, sendo este classificado como arenoso, o que corrobora com os resultados obtidos pela fluorescência de raios $\mathrm{X}$, que mostrou que os maiores porcentuais foram de óxidos de silício. A relação silte/argila, consequentemente, foi elevada e correspondente a 21 .

Em relação às características físico-químicas, os valores de $\mathrm{pH}$ do solo em água foram de 6,5 a 6,6 e estão ligeiramente acima daqueles encontrados em $\mathrm{KCl}$ (6,1 a 6,2), demonstrando que o mesmo apresenta carga líquida negativa. Esta carga pode ser devida aos contaminantes adsorvidos: alcoóis, ftalatos e adipatos.

Embora seja um solo contaminado, o teor de carbono orgânico foi de $0,93 \pm 0,12 \%$ e está dentro da faixa de valores considerada típica para solos tropicais. Fassbender ${ }^{27}$ compilou dados de teor de carbono orgânico de 91 amostras de solo do Brasil, obtidos por diferentes autores, e concluiu que deste total, $50 \%$ apresentavam valores entre 0,5 e $2,0 \%$; somente $10 \%$ ultrapassavam $4 \%$ e $5 \%$ estavam abaixo de $0,5 \%$. O baixo teor de ferro $(36 \pm 1 \mathrm{mg} / \mathrm{kg}$ ) corrobora os resultados encontrados por espectrometria de fluorescência de raio x. Os teores de nitrogênio e fósforo totais foram de $265 \pm 0$ e 2,3 \pm 0,6 mg/kg, respectivamente, sendo as relações carbono/nitrogênio $(\mathrm{C} / \mathrm{N})$ de 31 a 39 e carbono/fósforo (C/P) de 2700 a 5200 . Considerando as relações C/N 60:1 e C/P 300:1 recomendadas pela Norma CETESB L6.350, ${ }^{22}$ para a biodegradação de compostos orgânicos no solo, seria necessária a adição de fósforo para a manutenção da atividade dos micro-organismos indígenas e a biodegradação dos contaminantes.

\section{Densidade aparente, umidade residual, capacidade de} campo e pH

O valor de umidade residual da amostra Branco 1, após preparação e secagem por 4 dias, foi 7,6 $\pm 0,6 \%$; o da densidade, 1,18 $\pm 0,06$ $\mathrm{g} / \mathrm{cm}^{3}$; o da capacidade de campo, $38 \pm 1 \%$ e a faixa de variação de $\mathrm{pH}$, 5,6 a 5,8. A amostra Branco 2 apresentou umidade de 26,7 $\pm 0,2 \%$, densidade de 1,48 $\pm 0,02 \mathrm{~g} / \mathrm{cm}^{3}$ e pH 5,3 a 5,4. Estas determinações foram realizadas sem peneiramento da amostra, pois a mesma se apresentava extremamente plastificada e oleosa.

\section{Caracterização química do solo}

Os teores de alcoóis e plastificantes encontrados nas amostras de solo Branco1 e Branco 2 são mostrados na Tabela 3.

Tabela 3. Teores de alcoóis e plastificantes nas amostras de solo Branco1, Branco 2 e Lodo (inóculo)

\begin{tabular}{lcccccc}
\hline & \multicolumn{2}{c}{ Solo Branco1 } & \multicolumn{2}{c}{ Solo Branco2 } & \multicolumn{2}{c}{ Inóculo } \\
Compostos & $\begin{array}{c}\text { Média } \\
\mathrm{mg} / \mathrm{kg}\end{array}$ & $\begin{array}{c}\text { Desvio } \\
\text { padrão } \\
\mathrm{mg} / \mathrm{kg}\end{array}$ & $\begin{array}{c}\text { Média } \\
\mathrm{mg} / \mathrm{kg}\end{array}$ & $\begin{array}{c}\text { Desvio } \\
\text { padrão } \\
\mathrm{mg} / \mathrm{kg}\end{array}$ & $\begin{array}{c}\text { Média } \\
\mathrm{mg} / \mathrm{L}\end{array}$ & $\begin{array}{c}\text { Desvio } \\
\text { padrão } \\
\mathrm{mg} / \mathrm{L}\end{array}$ \\
\hline 2-etil-hexanol & 351 & 70 & 1519 & 267 & $\mathrm{nd}$ & - \\
isodecanol & 3765 & 199 & 6359 & 147 & $\mathrm{nd}$ & - \\
di-isobutilftalato & 2809 & 51 & 2193 & 76 & 10 & 1 \\
dibutilftalato & 2020 & 45 & 1635 & 53 & 5 & 0 \\
di-isoamilftalato & 3069 & 79 & 2545 & 51 & 2 & 0 \\
dioctiladipato & 181 & 4 & 155 & 3 & 3 & 1 \\
dietil-hexilftalato & 4770 & 98 & 3894 & 212 & 32 & 3 \\
di-isodecilftalato & 15054 & 432 & 11001 & 429 & 49 & 2 \\
\hline
\end{tabular}

nd - não detectado; limite detecção: $100 \mu \mathrm{g} / \mathrm{L}$

\section{Caracterização microbiológica do solo}

A densidade de bactérias heterotróficas para a amostra Branco 1 foi de 7,0 $\pm 2,6 \times 10^{3} \mathrm{UFC} / \mathrm{g}$ e para a Branco 2, de 7,7 $\pm 4,1 \times 10^{6}$ $\mathrm{UFC} / \mathrm{g}$. Foram consideradas apenas as placas onde o número de pontos representando unidades formadoras de colônias (UFC) estava entre 30 e 300, em diluições consecutivas. A primeira amostra apresentou um número de organismos bem inferior à segunda, o que indica a influência da secagem da amostra e a inadequação deste procedimento para o ensaio de biodegradação.

\section{Amostragem e caracterização do inóculo}

A faixa de variação do $\mathrm{pH}$ foi de 6,81 a 6,83 , temperatura 29,5 ${ }^{\circ} \mathrm{C}$ e densidade 0,986 a $0,990 \mathrm{~g} / \mathrm{cm}^{3}$. As concentrações de sólidos em suspensão totais e voláteis foram de 25 e $22 \mathrm{~g} / \mathrm{L}$, respectivamente. A densidade de bactérias heterotróficas no inóculo foi de 2,1 $\pm 0,4 \mathrm{x}$ $10^{8} \mathrm{UFC} / \mathrm{mL}$. Os teores de carbono orgânico total foram de 13600 a 14100 mg/L; nitrogênio total Kjeldahl de 1868 a 1887 mg/L e fósforo total de 204 a $207 \mathrm{mg} / \mathrm{L}$. Os teores de alcoóis e plastificantes no lodo podem ser visualizados na Tabela 3 .

\section{Monitoramento do ensaio de biodegradação}

\section{$p H$, temperatura e umidade}

A evolução do $\mathrm{pH}$ nos diferentes frascos é mostrada na Figura 1. Observa-se que todos os processos, com exceção dos correspondentes aos Brancos 1 e 2, apresentaram um aumento de $\mathrm{pH}$ nos 30 dias iniciais, com tendência à elevação deste parâmetro após este período nos frascos que receberam bactérias exógenas e com tendência ao decréscimo naqueles contendo apenas as bactérias indígenas. A diminuição de 
pH esperada, devido à degradação dos diésteres e formação de ácidos ftálicos, ${ }^{28,29}$ não foi observada no presente estudo (Frascos 3, 4, 5 e 6).

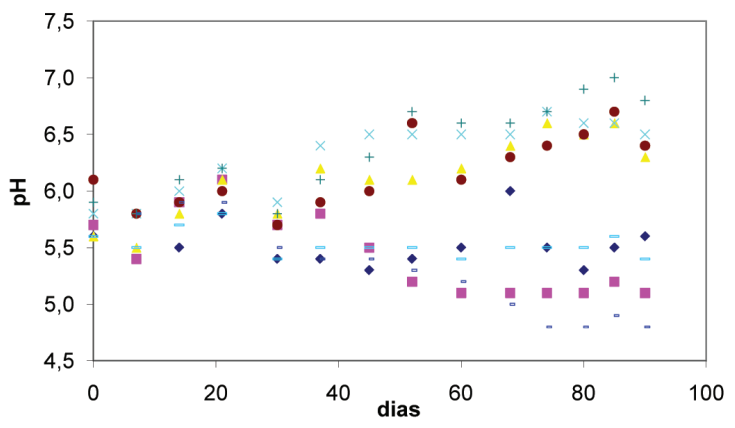

Figura 1. Evolução do PH nos ensaios de biodegradação. Frasco 1, - Frasco 2, $\triangle$ Frasco 3, $\times$ Frasco 4, $\bullet$ Frasco 5, + Frasco 6, - Frasco 7, - Frasco 8

A temperatura inicial e máxima do processo no Ensaio I foi de $29^{\circ} \mathrm{C}$ e no Ensaio II, $28^{\circ} \mathrm{C}$, sendo o menor valor $17^{\circ} \mathrm{C}$ após 60 dias, para os dois Ensaios.

Chang et al.$^{30}$ identificaram como condições ótimas para a biodegradação de oito ftalatos: pH igual a 7,0 e temperatura de $30^{\circ} \mathrm{C}$. Carrara ${ }^{31}$ observou a biodegradação de $100 \mathrm{mg} / \mathrm{kg}$ de DEHP no solo tropical por micro-organismos indígenas e exógenos adaptados, com remoções de $98,83 \%$, em faixa de $\mathrm{pH}$ em água entre 7,20 e 7,97 e temperaturas entre 24 e $27^{\circ} \mathrm{C}$. No presente estudo, as temperaturas foram mais baixas $(17$ a $29^{\circ} \mathrm{C}$ ) e os valores de $\mathrm{pH}$ diferentes $(5,5$ a 6,8$)$ dos pesquisados pelos autores mencionados anteriormente, no entanto, estas condições não se mostraram restritivas à biodegradação dos plastificantes.

Monitorando a umidade durante o período, observou-se que a inicial efetiva não correspondeu à teórica esperada (50\%) com a adição de água, lodo e solução de nutrientes, estando abaixo em todos os frascos. A água adicionada pode ter participado de reações de hidrólise dos diésteres carboxílicos. ${ }^{32}$ A plastificação do solo, que dificultou a homogeneização inicial, também pode ter contribuído para as diferenças encontradas. A umidade inicial variou de 34 a $45 \%$ para todos os frascos e a final, de 20 a 27\%. Após 90 dias, a umidade final estava abaixo da capacidade de campo do solo.

Embora a USEPA ${ }^{33}$ recomende operar os reatores em lama com teor de umidade na faixa de 40 a $80 \%$, foi constatada remoção dos contaminantes com os teores de umidade utilizados.

\section{Remoções dos contaminantes e densidade de bactérias heterotróficas}

As remoções dos contaminantes e densidade de bactérias heterotróficas estão mostradas na Tabela 4.

As elevadas remoções de contaminantes, observadas a partir de 30 dias, sugerem que além da biodegradação pelos micro-organismos indígenas (Frasco 2), outros mecanismos de remoção podem ter ocorrido, tais como a hidrólise dos plastificantes DEHP e DIDP.

As remoções de contaminantes sem o respectivo aumento na densidade de bactérias (Frascos 1, 7 e 8) podem ser explicadas pela não seletividade da contagem de bactérias heterotróficas, ${ }^{34}$ por cometabolismo ou, ainda, pelo fato de que os teores iniciais considerados foram os dos solos Branco 1 e 2, respectivamente, e não aqueles efetivamente presentes nos frascos no instante inicial, após adição de água.

Na contagem de bactérias heterotróficas, foram detectados valores entre 30 e 300 colônias em diferentes diluições das amostras de solo para o mesmo frasco. A repetibilidade entre as triplicatas também não foi observada. As propriedades dos contaminantes (altamente adsorvidos no solo), aliadas às características geotécnicas do solo arenoso e idade da contaminação, podem ter sido fatores interferentes para a aplicação da metodologia, justificando a não repetibilidade entre triplicatas, bem como a divergência de resultados em função do aumento das diluições das amostras.

Conforme resultados obtidos nos Frascos 3, 4, 5 e 6, pode-se observar que a introdução de inóculo e nutrientes foi essencial à biodegradação de alcoóis e plastificantes.

\section{Equações cinéticas de biodegradação}

Os teores de contaminantes na lama inicial, equação cinética, constantes de biodegradação e coeficientes de determinação à cinética de primeira ordem nos Frascos 3, 4, 5 e 6, que apresentaram as melhores remoções de poluentes, estão mostrados na Tabela 5. Os resultados obtidos indicam que a biodegradação dos alcoóis e plastificantes seguiu uma cinética de primeira ordem, da mesma forma que os observados por Zeng et al., ${ }^{35}$ com seis ftalatos e bactérias Pseudomonas fluoresences FS1.

A cinética de degradação para um determinado composto foi diferente nos diversos frascos, sugerindo que a degradação deste variou

Tabela 4. Remoções de alcoóis e plastificantes e densidade de bactérias heterotróficas

\begin{tabular}{|c|c|c|c|c|c|c|c|c|}
\hline \multirow{2}{*}{ Frasco } & \multirow{2}{*}{ Descrição } & \multirow{2}{*}{ Contaminante } & \multicolumn{3}{|c|}{ Remoções mínimas (\%) } & \multicolumn{3}{|c|}{ Crescimento bacteriano ( $\mathrm{Log})$} \\
\hline & & & 30 dias & 60 dias & 90 dias & 30 dias & 60 dias & 90 dias \\
\hline \multirow[t]{2}{*}{1} & \multirow[t]{2}{*}{ Umidade ajustada para $50 \%$} & Alcoóis & 90 & 96 & 96 & - & - & - \\
\hline & & Plastificantes & 95 & 98 & 98 & & & \\
\hline \multirow[t]{2}{*}{2} & \multirow{2}{*}{$\begin{array}{l}\text { Umidade ajustada para 50\%, adição: } \\
135 \mathrm{mg} \mathrm{N} / \mathrm{kg} \text { e } 30 \mathrm{mg} \mathrm{P} / \mathrm{kg}\end{array}$} & Alcoóis & 78 & 88 & 92 & & & 1 \\
\hline & & Plastificantes & 90 & 95 & 99 & & & \\
\hline \multirow[t]{2}{*}{3} & \multirow{2}{*}{$\begin{array}{c}\text { Umidade ajustada para 50\%, adição: } \\
\qquad 9 \mathrm{~g} \mathrm{SSV} / \mathrm{kg}\end{array}$} & Alcoóis & 92 & 98 & 99 & - & 1 & 1 \\
\hline & & Plastificantes & 69 & 93 & 92 & & & \\
\hline \multirow[t]{2}{*}{4} & \multirow{2}{*}{$\begin{array}{l}\text { Umidade ajustada para 50\%, adição: } \\
9 \mathrm{~g} \mathrm{SSV} / \mathrm{kg}, 135 \mathrm{mg} \mathrm{N} / \mathrm{kg} \text { e } 30 \mathrm{mg} \mathrm{P} / \mathrm{kg}\end{array}$} & Alcoóis & 81 & 90 & 93 & - & 1 & 1 \\
\hline & & Plastificantes & 9 & 96 & 93 & & & \\
\hline \multirow[t]{2}{*}{5} & \multirow{2}{*}{$\begin{array}{l}\text { Umidade ajustada para 50\%, adição: } \\
\qquad 11 \mathrm{~g} \mathrm{SSV} / \mathrm{kg}\end{array}$} & Alcoóis & 64 & 79 & 92 & - & 1 & 2 \\
\hline & & Plastificantes & 0 & 37 & 72 & & & \\
\hline \multirow[t]{2}{*}{6} & \multirow{2}{*}{$\begin{array}{c}\text { Umidade ajustada para 50\%, adição: } \\
11 \mathrm{~g} \mathrm{SSV} / \mathrm{kg}, 170 \mathrm{mg} \mathrm{N} / \mathrm{kg} \text { e } 37 \mathrm{mg} \mathrm{P} / \mathrm{kg}\end{array}$} & Alcoóis & 83 & 92 & 97 & - & - & 1 \\
\hline & & Plastificantes & 6 & 36 & 84 & & & \\
\hline \multirow[t]{2}{*}{7} & \multirow{2}{*}{$\begin{array}{l}\text { Umidade ajustada para 50\%, adição: } \\
170 \mathrm{mg} \mathrm{N} / \mathrm{kg} \text { e } 37 \mathrm{mg} \text { P/kg }\end{array}$} & Alcoóis & 24 & 65 & 77 & - & - & - \\
\hline & & Plastificantes & 0 & 52 & 58 & & & \\
\hline \multirow[t]{2}{*}{8} & Umidade ajustada para $50 \%$ & Alcoóis & 67 & 89 & 94 & - & - & $(-1)$ \\
\hline & & Plastificantes & 0 & 58 & 74 & & & \\
\hline
\end{tabular}


Tabela 5. Teores de contaminantes na lama inicial, equação cinética, constantes de biodegradação e coeficientes de correlação na biodegradação

\begin{tabular}{|c|c|c|c|c|c|c|c|c|}
\hline \multirow{2}{*}{ Composto } & \multicolumn{4}{|c|}{ Frasco 3} & \multicolumn{4}{|c|}{ Frasco 4} \\
\hline & Teores & Equação cinética & $\mathrm{k}$ & $\mathrm{r}^{2}$ & Teores & Equação cinética & $\mathrm{k}$ & $\mathrm{r}^{2}$ \\
\hline IDA & 3765 & $y=13,885 e^{-0,0446 x}$ & 0,0446 & 0,8952 & 3765 & $\mathrm{y}=16,803 \mathrm{e}^{-0,0292 x}$ & 0,0292 & 0,9027 \\
\hline DIBP & 2809 & $y=2,9297 e^{-0,0673 x}$ & 0,0673 & 0,7956 & 2809 & $y=6,2235 e^{-0,0752 x}$ & 0,0752 & 0,9359 \\
\hline DBP & 2020 & $y=2,3268 e^{-0,0642 x}$ & 0,0642 & 0,8093 & 2020 & $y=4,6413 e^{-0,0775 x}$ & 0,0775 & 0,9460 \\
\hline DIAP & 3069 & $\mathrm{y}=4,0594 \mathrm{e}^{-0,071 \mathrm{x}}$ & 0,0710 & 0,8831 & 3069 & $\mathrm{y}=6,4358 \mathrm{e}^{-0,071 \mathrm{x}}$ & 0,0710 & 0,9292 \\
\hline DEHP & 4770 & $\mathrm{y}=9,3729 \mathrm{e}^{-0,0248 x}$ & 0,0248 & 0,8627 & 4770 & $y=17,573 e^{-0,0546 x}$ & 0,0546 & 0,8742 \\
\hline DIDP & 15054 & $\mathrm{y}=23,963 \mathrm{e}^{-0,0345 \mathrm{x}}$ & 0,0345 & 0,9086 & 15054 & $\mathrm{y}=44,983 \mathrm{e}^{-0,0487 \mathrm{x}}$ & 0,0487 & 0,8776 \\
\hline \multirow{2}{*}{ Composto } & \multicolumn{4}{|c|}{ Frasco 5} & \multicolumn{4}{|c|}{ Frasco 6} \\
\hline & Teores & Equação cinética & $\mathrm{k}$ & $\mathrm{r}^{2}$ & Teores & Equação cinética & $\mathrm{k}$ & $\mathrm{r}^{2}$ \\
\hline IDA & 6359 & $\mathrm{y}=37,32 \mathrm{e}^{-0,0267 \mathrm{x}}$ & 0,0267 & 0,988 & 6359 & $\mathrm{y}=31,523 \mathrm{e}^{-0,0394 \mathrm{x}}$ & 0,0394 & 0,9706 \\
\hline DIBP & 2193 & $\mathrm{y}=4,116 \mathrm{e}^{-0,0489 \mathrm{x}}$ & 0,0489 & 0,8844 & 2193 & $y=4,1618 e^{-0,0562 x}$ & 0,0562 & 0,9126 \\
\hline DBP & 1635 & $\mathrm{y}=3,0536 \mathrm{e}^{-0,0549 \mathrm{x}}$ & 0,0549 & 0,9048 & 1635 & $\mathrm{y}=2,5899 \mathrm{e}^{-0,046 \mathrm{x}}$ & 0,0460 & 0,7876 \\
\hline DIAP & 2545 & $y=4,5842 e^{-0,0466 x}$ & 0,0466 & 0,8957 & 2545 & $\mathrm{y}=5,1103 \mathrm{e}^{-0,0447 x}$ & 0,0447 & 0,8766 \\
\hline DOA & 155 & $\mathrm{y}=0,7242 \mathrm{e}^{-0,0184 \mathrm{x}}$ & 0,0184 & 0,7302 & 155 & $\mathrm{y}=0,6401 \mathrm{e}^{-0,026 \mathrm{x}}$ & 0,0260 & 0,8990 \\
\hline DEHP & 3894 & $\mathrm{y}=13,751 \mathrm{e}^{-0,018 \mathrm{x}}$ & 0,0180 & 0,8079 & 3894 & $\mathrm{y}=12,892 \mathrm{e}^{-0,0217 \mathrm{x}}$ & 0,0217 & 0,8860 \\
\hline DIDP & 11001 & $\mathrm{y}=32,519 \mathrm{e}^{-0,0156 \mathrm{x}}$ & 0,0156 & 0,8045 & 11001 & $\mathrm{y}=33,066 \mathrm{e}^{-0,0195 \mathrm{x}}$ & 0,0195 & 0,7900 \\
\hline
\end{tabular}

Y: teor de contaminante (mmol/kg) e x: tempo(dias); k: constante de degradação (1/dia); $\mathrm{r}^{2}$ - coeficiente de correlação; Teores: Teores iniciais na lama (mg/kg);

IDA:isodecanol; DIBP:di- isobutilftalato; DBP:dibutilftalato; DIAP: di-isoamilftalato; DOA: dioctiladipato; DEHP: dietil-hexilftalato; DIDP: di-isodecilftalato

com a presença dos demais compostos. Neste estudo, entretanto, não foi observada necessariamente a diminuição da constante de biodegradação em função do aumento dos teores iniciais de plastificantes, conforme constatado por Zeng et al., ${ }^{35}$ bem como não houve diminuição na constante de degradação dos ftalatos em função do aumento e ramificação da cadeia alquílica, em um mesmo reator. Por outro lado, os alcoóis, por serem cossubstratos de cadeias mais simples que os plastificantes, não foram degradados mais rapidamente, mesmo estando presentes em todos os frascos.

Considerando apenas os valores de $\mathrm{k}$ para o DEHP nos diversos frascos, para atingir o valor de $10 \mathrm{mg}$ DEHP/kg solo, recomendado pela CETESB para solo industrial, seriam necessários 238 dias no Frasco 3, 120 dias no Frasco 4, 349 dias no Frasco 5 e 286 dias no Frasco 6.

\section{CONCLUSÕES}

Dos resultados obtidos, pode-se concluir que não foi necessário o ajuste do $\mathrm{pH}$ do solo para a biodegradação dos alcoóis e plastificantes; não sendo, portanto, recomendada a Norma CETESB L.6350 para preparação do solo no ensaio de biodegradação.

A densidade de bactérias heterotróficas não foi um bom indicador da biodegradação no solo, não sendo recomendada a adaptação da Norma CETESB L5.201.

As melhores remoções de plastificantes e alcoóis por biodegradação foram obtidas com a adição de inóculo adaptado (lodo), proveniente do conteúdo do tanque de aeração do sistema de lodos ativados que trata as águas residuárias da indústria de plastificantes.

A presença dos alcoóis (cossubstratos) e de plastificantes de menor cadeia alquílica não impediu a biodegradação dos plastificantes de cadeia alquílica longa e ramificada: DEHP e DIDP.

$\mathrm{O}$ declínio de $\mathrm{pH}$ na biodegradação de plastificantes não foi observado no presente estudo.

A biodegradação dos alcoóis, ftalatos e adipatos no solo contaminado seguiu uma cinética de primeira ordem.

Em pH entre 5,5 a 6,8, temperatura de 17 a $29^{\circ} \mathrm{C}$, umidade inicial de 34 a 45\%, adição de 9 a 11 g de sólidos em suspensão voláteis (SSV) por kilograma de solo, relações carbono:nitrogênio e carbono:fósforo de 60:1 e 300:1, respectivamente, foram obtidas remoções superiores a $72 \%$ de plastificantes após 90 dias, sendo que os teores iniciais va- riaram de $153 \mathrm{mgDOA} / \mathrm{kg}$ a $15552 \mathrm{mgDIDP} / \mathrm{kg}$. Os teores finais para o DEHP, após 90 dias, variaram de 85 a $870 \mathrm{mgDEHP} / \mathrm{kg}$ solo, sendo necessários de 120 a 349 dias para atingir os $10 \mathrm{mg} \mathrm{DEHP/kg}$ solo industrial recomendados pela CETESB. Os teores finais de DIDP foram de 311 a 3113 mg DIDP/kg após 90 dias; no entanto, este último não consta na lista de valores de referência da CETESB, recomendando-se a inclusão deste composto, uma vez que as indústrias estão substituindo o DEHP pelo DIDP no processo produtivo.

\section{REFERÊNCIAS}

1. Brown, D.; Thompson, R. S.; Stewart, K. M.; Croudace, C.; Gillings, E.; Chemosphere 1996, 32, 2177.

2. U. S. Department of Health and Human Services - Agency for Toxic Substances and Disease Registry (ATSDR); Toxicological profile for di(2-ethylhexil)phthalate, 2002.

3. Meek, M. E.; Chan, P. K. I.; J. Environ. Sci. Health 1994, 12, 179.

4. NTP Center for the evaluation of risks to human reproduction; Reprod. Toxicol. 2002, 6, 529.

5. Staples, C. A.; Parkerton, T. F.; Peterson, D. R.; Chemosphere 2000, 40, 885.

6. Morita, D. M.; Moura, A. N.; Carrara, S. M. C. M. Em Aspectos relativos à poluição do solo; Pinto, T. J. A.; Vitolo, M.; Tenuta Filho, A.; Mardegan, Y. M. L., eds.; Guanabara Koogan: Rio de Janeiro, 2009.

7. U.S.Environmental Protection Agency; Superfund Annual Report, 2007.

8. http://basol.environnement.gouv.fr/tableaux/home.htm, acessada em Maio 2008 e Agosto 2010.

9. http://www.ovam.be/jahia/Jahia/pid/991?lang=en, acessada em Maio 2008 e Agosto 2010.

10. Wesselink, L. G.; Notenboom, J.; Tiktak, A.; The consequences of the European Soil Framework Directive for Dutch policy, Netherlands Environmental Assessment Agency: The Netherlands, 2006.

11. http://www.umweltbundesamt.at/umweltinformation/umweltkontrollbericht/ ukb2007/ukb8_altlasten/, acessada em Maio 2008 e Agosto 2010.

12. Secretaria de Vigilância em Saúde, Departamento de Análise de Situação em Saúde; Saúde Brasil 2007: uma análise da situação de saúde, Ministério da Saúde: Brasília, 2007, p. 641 e 677.

13. http://www.cetesb.sp.gov.br/Solo/areas_contaminadas/texto_areas_cont_ nov_08.pdf, acessada em Agosto 2009 e Agosto 2010.

14. Jianlong, W.; Xuan, Z.; Weizhong, W.; Process Biochem. 2004, 39, 837. 
15. Di Gennaro, P.; Collina, E.; Franzetti, A.; Lasagni, M.; Luridiana, A.; Pitea, D.; Bestetti, G.; Environ. Sci. Technol. 2005, 39, 325.

16. Semple, K. T.; Morriss, A. W. J.; Paton, G. I.; J. Soil Sci. 2003, 54, 809.

17. Pastore, E. L.; Fontes, R. M. Em Caracterização e Classificação dos Solos; Oliveira, A. M. S.; Brito, S. N. A., eds.; Associação Brasileira de Geologia de Engenharia: São Paulo, 1998.

18. Lepsch, I. F.; Formação e conservação dos solos, Oficina de Textos: São Paulo, 2002.

19. Salomão, F. X. T.; Antunes, F. S. Em Solos em Pedologia; Oliveira, A. M. S.; Brito, S. N. A., eds.; Associação Brasileira de Geologia de Engenharia: São Paulo, 1998.

20. Instituto Agronômico de Campinas; Análises químicas para avaliação da fertilidade de solos tropicais, IAC: Campinas, 2001.

21. Embrapa - Empresa Brasileira de Pesquisa Agropecuária; Manual de análises químicas de solos, plantas e fertilizantes, Embrapa comunicação para transferência de tecnologia: Brasília,1999.

22. Companhia de Tecnologia e Saneamento Ambiental do Estado de São Paulo (CETESB); Determinação da biodegradação de resíduos método respirométrico de Bartha, Norma L6 350, CETESB: São Paulo, 1990.

23. Companhia de Tecnologia e Saneamento Ambiental do Estado de São Paulo. (CETESB); Bactérias heterotróficas - contagem em placas, Norma ${ }^{\circ}$ L5.201, CETESB: São Paulo, 1996.

24. http://www.epa.gov/osw/hazard/testmethods/sw846/index.htm, acessada em Agosto 2008 e Agosto 2010.
25. American Public Health Association (APHA), Water Works Association (AWWA), Water Environmental Federation (WEF); Standard methods for the examination of water and wastewater, $20^{\text {th }}$ ed., APHA-WEF: Washington, 1998.

26. http://mapas.ibge.gov.br/solos/viewer.htm, acessada em Novembro 2005 e Agosto 2010.

27. Fassbender, H. W.; Química de suelos, Instituto interamericano de ciencias agrícolas de la OEA: Turrialba,1975.

28. Staples, C. A.; Peterson, D. R.; Parkerton, T. F.; Adams, W. J.; Chemosphere 1997, 35,667.

29. Juneson, C.; Ward, O. P.; Singh, A.; Process Biochem. 2001, 37, 305.

30. Chang, B. V.; Yang, C. M.; Cheng, C. H.; Yuan, S. Y.; Chemosphere 2004, 55, 533 .

31. Carrara, S. M. C. M.; Tese de Doutorado, Universidade de São Paulo, Brasil, 2003.

32. Afghan, B. K.; Chau, A. S. Y.; Analysis of Trace Organics in the Aquatic Environment, CRC Press: Boca Raton, 1989, p. 989.

33. http://www.epa.gov/waterscience/library/sediment/remediation.pdf, acessada em Maio 2003 e Agosto 2010.

34. Lloyd-Jones, G.; Laurie, A. D.; Hunter, D. W. F.; Fraser, R.; FEMS Microbiol. Ecol. 1999, 29, 69

35. Zeng, F.; Cui, K.; Li, X.; Fu, J.; Sheng, G. ; Process Biochem. 2002, 39 , 1125 . 